\title{
Thermal Balance of the Newborn Infant in a Heat-gaining Environment
}

\author{
E. Sulyok, ${ }^{[11]}$ E. JÉquier, and L. S. Prod'hom \\ Departments of Pediatrics and Clinical Physiology, University Medical School, Lausanne, Switzerland
}

\section{Extract}

The thermal balance of 22 full term, 9 small for date, and 8 large premature infants was studied by gradient layer direct calorimetry on the 1st day of life. In addition, the influence of muscular activity on the ability to sweat of 8 full term infants was investigated. The same measurements were repeated in 20 infants on the 3rd day of life.

All i nfants were subjected to the same experimental conditions: ambient temperature $37^{\circ}, \mathrm{re}^{\mathrm{r}}$ ative humidity $50 \%$, and air flow 30 liters $/ \mathrm{min}$.

It was demonstrated that the evaporation of water was the primary way to dissipate heat in a heat-gaining environment. Active thermoregulatory sweating was elicited at deep body temperatures of $37.45^{\circ}, 37.8^{\circ}$, and $37.76^{\circ}$ in the full term, small for date, and premature infants, respectively.

The set-point temperature of sweating tended to be lower with increasing gestational and postnatal age, and with vigorous muscular activity. The physiologic weight loss of about $3 \%$, and the intrauterine growth retardation resulted in significant increase in this threshold temperature.

The maximal sweat rate of the premature infants $(1.43 \mathrm{~W} / \mathrm{kg})$ was significantly lower than that of the full term $(1.81 \mathrm{~W} / \mathrm{kg})$ and small for date infants $(2.32 \mathrm{~W} / \mathrm{kg})$ : $P<0.05$ and 0.01 , respectively.

Heat loss by radiation and convection was directly related to the mean skin temperature; it was only when the latter reached the value of $37^{\circ}$ that radiative plus convective heat loss became positive.

There was a close inverse relation between the total heat loss and heat storage. After the beginning of sweating, the heat storage of full term and small for date infants sharply decreased and stabilized around 0 , which showed that a new thermal steady state was reached. The premature infant was not able to reach this new equilibrium and the heat storage remained positive.

The full term and small for date infants could keep the body temperature at a steady level of $37.66^{\circ}$ and $37.98^{\circ}$, respectively, whereas the esophageal temperature of the premature infants kept on increasing.

The cutaneous thermal conductance, an indicator of the heat-transferring blood flow, was at first negative, which showed that heat was transferred from the surface to the core. Later, before the evaporative heat loss, it increased and reached the maximal value at a body temperature of $37.6^{\circ}$ in the normal, and of $37.9^{\circ}$ in both the small for date and premature groups.

The metabolic rate for the small for date and premature infants was significantly higher than that for the full term infants, and it directly related to the deep body temperature in each group. 
In the new thermal equilibrium, the metabolic rate of the full term infants was about $20 \%$ lower than that measured under neutral ambient conditions. We suggest that the term "neutral thermal environment" must be reconsidered.

\section{Speculation}

A new method, gradient layer direct calorimetry, gave us the opportunity to measure directly the different heat losses of the neonate under well controlled experimental conditions, and to compare these data with the results obtained by indirect calorimetry.

\section{Introduction}

Brück [6] was the first to describe the essential criteria of homeotherm behavior in both full term and premature infants on the lst day of life. He was able to demonstrate not only maximal vasoconstriction and metabolic response to cold, but also vasodilatation and sweat reaction in a warm environment.

During the last 10 years most studies have been focused on investigation of the neutral temperature range, the minimal oxygen consumption, and the metabolic response to cold. Attempts have also been made to examine the various factors upon which the basal metabolic rate depends.

Knowledge of the thermoregulatory response of the neonate to a warm environment immediately after birth is more scant, although in a few cases vasomotor reaction, ability to sweat, or metabolic response were studied separately during the neonatal period. However, with regard to the complexity of the thermal balance in a warm environment, such studies could not produce enough information to provide understanding of the relation between the various physiologic events.

Inasmuch as almost all of the previous studies were performed by indirect calorimetry, it was of great interest to measure the various physiologic responses by direct calorimetry. Construction of a gradient layer calorimeter according to Benzinger's principle [4] allowed us to perform an extensive study on the dynamics of metabolic response of the neonate by direct, continuous measurements of convective, radiative, and evaporative heat losses.

The present study was carried out to estimate the efficiency of the different heat-dissipating mechanisms and to compare the ability of the full term, full sized, small for date, and premature infants to reach and to maintain thermal equilibrium in a heat-gaining environment on the 1st day of life.

\section{Materials and Methods}

Forty-seven newborn infants were studied on the 1st day of life. The consent of their parents was obtained in every case before the experiment. In all cases the pregnancy and the delivery were uneventful, and all infants were vigorous immediately after birth with an Apgar score of 8 or more at the 1st min of age.

The infants were divided into four groups as follows.

\section{Group I}

Twenty-two infants in this group with birth weights which ranged from 2,890 to $3,920 \mathrm{~g}$ (mean 3,419 g), all appropriate for gestational age (range 38-42 weeks; mean 39.9 weeks), were studied.

\section{Group II}

The nine small for date infants of this group had birth weights of 2,253-2,666 $\mathrm{g}$ (mean 2,486 g) and gestational ages of $39-43$ weeks (mean 41 weeks). Their weight fell below the 10th percentile curve of Lubchenco's standard [28].

\section{Group III}

This group was constituted by eight "large" premature infants, just on the borderline of prematurity with birth weights of 2,130-2,920 $\mathrm{g}$ (mean 2,560 $\mathrm{g}$ ) and gestational ages of 35-37 weeks (mean 36.1 weeks).

\section{Group IV}

The eight infants in this group were studied separately because of their continuous, intensive activity accompanied by crying and restlessness. The birth weights and gestational ages of these infants varied between 2,690 and 3,566 $\mathrm{g}$ (mean 3,154 g) and 40 and 43 weeks (mean 40.9 weeks), respectively.

The study was completed by repetition of examina- 
tions in 20 cases on the 3rd day of life in order to obtain information about the effect of initial weight loss on the heat-dissipating ability of the neonate.

All experiments were carried out in a gradient layer direct calorimeter at ambient temperature $37^{\circ}$, relative humidity $50 \%$, and air flow $30 \mathrm{liter} / \mathrm{min}$.

The infants were examined before being fed on the first day, and again on the 3rd day of life about $2 \mathrm{hr}$ after the last feeding.

The experiment usually lasted $90 \mathrm{~min}$ and was stopped when a steady state of evaporative heat loss and internal temperature was reached for at least 5-10 $\min$.

The infants wore nothing except for a urine bag, and were fixed in a supine position to a special bed. If there was any leakage of urine or meconium during the study, the experiment was not evaluated.

The infant was carefully watched during the whole experimental period and activity was checked every 2 min according to the arbitrary scale used by Brück $e t$ al. [7]. Only infants with an activity level of -4 (eyes closed, no movement) were included in the study (apart from group $I V$ ). The respiratory rate was counted every $10 \mathrm{~min}$. The evaporative, dry, and total heat losses as well as esophageal [37] and mean skin temperatures were continuously recorded.

The skin temperature was recorded at six different sites (forehead, upperarm, abdomen, thigh, hand, and foot [38]), and weighing factors, derived from the data of Silverman and Agate [32], were used to obtain the mean skin temperature.

\section{Dry Heat Loss Measurements}

The calorimeter forms a cavity of 80 by 30 by $30 \mathrm{~cm}$. The inner surfaces are completely covered with a gra- dient layer which allows the measurement of heat losses by radiation and convection (dry heat losses). The gradient layer (Fig. 1) consists of a plate of expoxy resin $2.4 \mathrm{~mm}$ thick with a printed circuit of nickel on both sides. The electric resistance of the circuits is a function of the temperature. The inner and outer circuits are connected to form a Wheatstone bridge which is supplied by a constant current.

The measurement of the heat flow from the infant is based upon the principle of the law of Fourier on the conduction of heat; this law states that the heat flow through a layer of a given surface, thickness, and thermal conductivity is proportional to the difference of temperature between the two surfaces of the layer (Fig. 1). With our layer, it is easy to demonstrate that the voltage measured with the Wheatstone bridge is directly proportional to the heat flow. For this measurement, the outer surface of the gradient layer must be maintained at a constant temperature. This is obtained by a rapid circulation of water inside the walls of the calorimeter; the water temperature is very precisely regulated at a set temperature with maximal variations of $\pm 0.01^{\circ}$.

The calibration of the calorimeter was performed with a source of electric heat (a resistance made of a long constantan wire) connected to a high quality wattmeter. A nearly perfect correlation was found between the heat output and the heat measured by the gradient layer. The gradient layer response changed less than $0.25 \%$ when a given amount of heat was measured at a temperature varying from $20^{\circ}$ to $40^{\circ}$.

\section{Evaporative Heat Loss Measurement}

Air passes through the calorimeter in an open circuit (Fig. 2). Fresh air is constantly forced through the

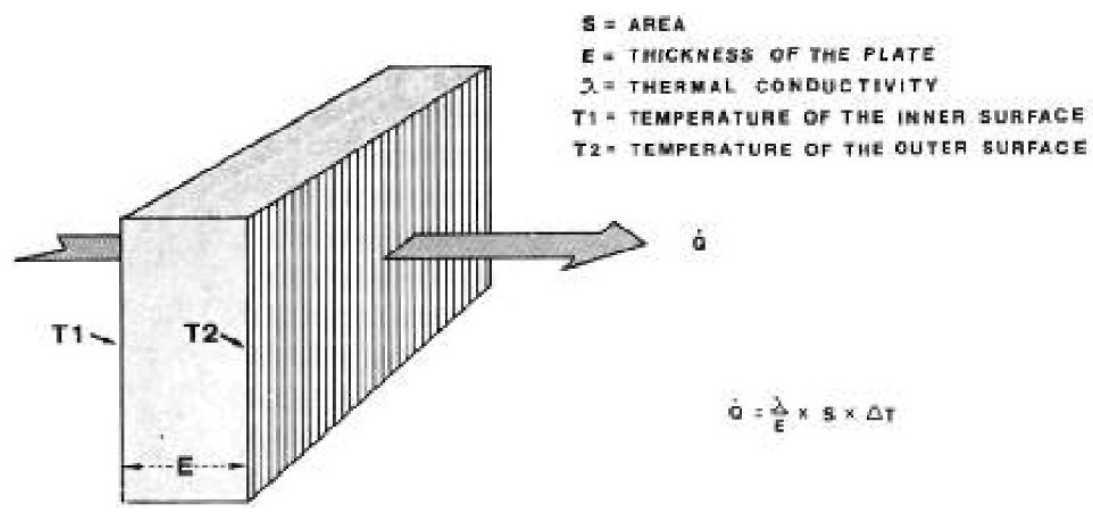

Fig. 1. Gradient layer. In accordance with Fourier's law on thermal conduction, the amount of heat ( $\dot{\mathrm{Q}})$ going through the plate is: $\dot{\mathrm{Q}}=$ $\lambda / \mathrm{E} \times \mathrm{S} \times \mathrm{T}$, where $\mathrm{T}$ represents the temperature gradient across the plate. 
calorimeter at a rate of 30 liters $/ \mathrm{min}$. Before reaching the calorimeter, the air is first saturated at a low temperature, $T_{0}$, in a heat exchanger, the "saturator." The temperature, $T_{0}$, is determined according to the relative humidity chosen for the experiment. Then, heat is added to the air in a second heat exchanger, the "heater," until it has reached the calorimeter temperature. The air passes through the calorimeter and carries away the water vapor lost by the baby. Outgoing air from the chamber passes into a third heat exchanger, the "condenser," which is maintained at the low temperature, $\mathbf{T}_{\mathbf{0}}$, the same temperature at which the air was previously saturated. In the condenser, the water vapor lost by the infant condenses out and gives up its latent heat which is measured by a gradient layer. At the outlet of the condenser, the air has resumed saturation at the temperature $T_{0}$. The evaporative heat loss of the infant is obtained by subtracting the heat given by the heater to the heat measured in the condenser. Total heat loss is the sum of dry and evaporative heat losses.

\section{Calculation}

The heat storage $(\Delta \dot{S})$ was calculated by assuming that the core represented $60 \%$ and the skin $40 \%$ of the whole body temperature [32] as follows: $\Delta \dot{S}=m_{b} \times c_{b}$ $\times\left(0.6 \Delta \mathrm{T}_{\mathrm{i}}+0.4 \Delta \mathrm{T}_{\mathrm{s}}\right) / \Delta \mathrm{t}$, where $\mathrm{m}_{\mathrm{b}}=$ body weight; $c_{b}=$ specific heat of body mass $=0.84 \mathrm{Cal} \mathrm{kg}^{-1}{ }^{\circ} \mathrm{C}^{-1}$; $\Delta T_{i}=$ variation of internal temperature; $\Delta T_{s}=$ variation of mean skin temperature; and $\Delta_{t}=$ time internal. The metabolic rate was calculated from the formula of heat balance [22]: metabolic rate $=$ heat losses + heat storage. The cutaneous thermal conductance was determined according to the formula suggested by Hardy and Soderstrom [22]: conductance $=$ [rate of cutaneous heat losses]/[body surface $\times\left(T_{i}-\bar{T}_{s}\right)$ ] where $\mathbf{T}_{i}$ is the internal and $\overline{\mathbf{T}}_{\mathrm{s}}$ is the mean skin temperature.

For statistical analysis the means and SE were calculated for every $5 \mathrm{~min}$ before, and for every $2 \mathrm{~min}$ after the beginning of sweating. The $P$ values presented were determined by Student's $t$ test.

\section{Units of Measure}

The heat losses, heat storage, and metabolic rate were expressed in watts.

For purposes of comparison with the results obtained by indirect calorimetry; $1 \mathrm{~W}=14.334 \mathrm{cal} / \mathrm{min}$ $=0.860 \mathrm{Cal} / \mathrm{hr}=2.975 \mathrm{ml} \mathrm{O}$. ing that $1 \mathrm{ml} \mathrm{O} \mathrm{O}_{2}$ consumed $/ \mathrm{min}$ is equal to $4.825 \mathrm{cal} /$

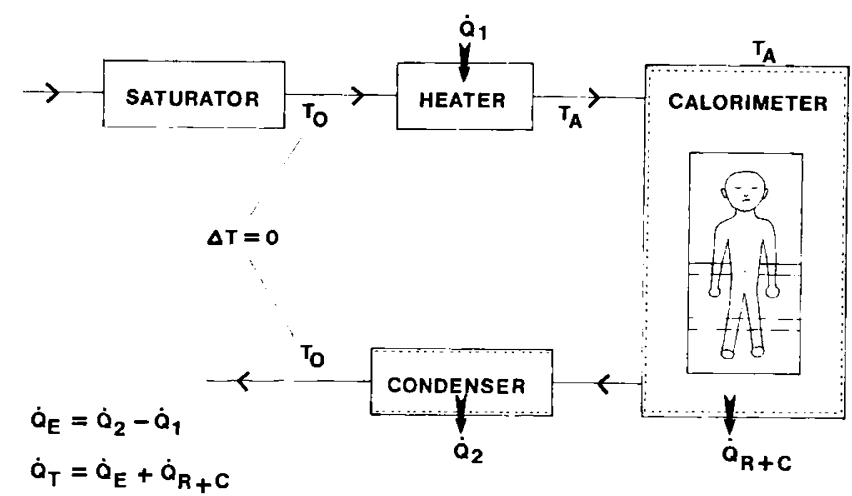

Fig. 2. Scheme of the open air circuit of the calorimeter. Gradient layers are shown by $---\dot{Q}_{E}$ : evaporative heat loss; $\dot{Q}_{R+C}$ : radiative and convective heat loss; $\dot{Q}_{r}$ : total heat loss.

min). Cutaneous thermal conductance was expressed in calories per second per square meter, at a set temperature, degrees Centigrade.

\section{Results}

\section{Heat Losses}

The changes in evaporative, dry, and total heat losses are shown in Figures 3 and 4 . The evaporative heat loss was very stable and of about the same extent in each group of infants before the sweating. The sweat response of the normal neonate was elicited about 35 to $40 \mathrm{~min}$ after exposure to an ambient temperature of $37^{\circ}$, at an esophageal temperature of $37.45^{\circ}$. The maximal rate of sweating was about 4 times higher than the basal values and was reached 35 min after the onset of active sweating.

In the small for date group, the sweat reaction began 55-60 min after exposure to a hot environment; However, the sweat rate increased more rapidly, and the maximal value obtained was 5 times higher than the basal value of the evaporative heat loss. The changes with time of the evaporative heat loss in the premature group were similar to those of the small for date infants, but the maximal rate of sweating remained significantly lower as compared with any group.

Two different types of sweat response were observed in individual cases. The more common type was represented by repeated increase in evaporative heat loss, followed by a more or less long plateau. Less frequently, we found a rather rapid and continuously increasing sweat reaction.

In Figure $5 a$, the evaporative heat loss is shown as a 


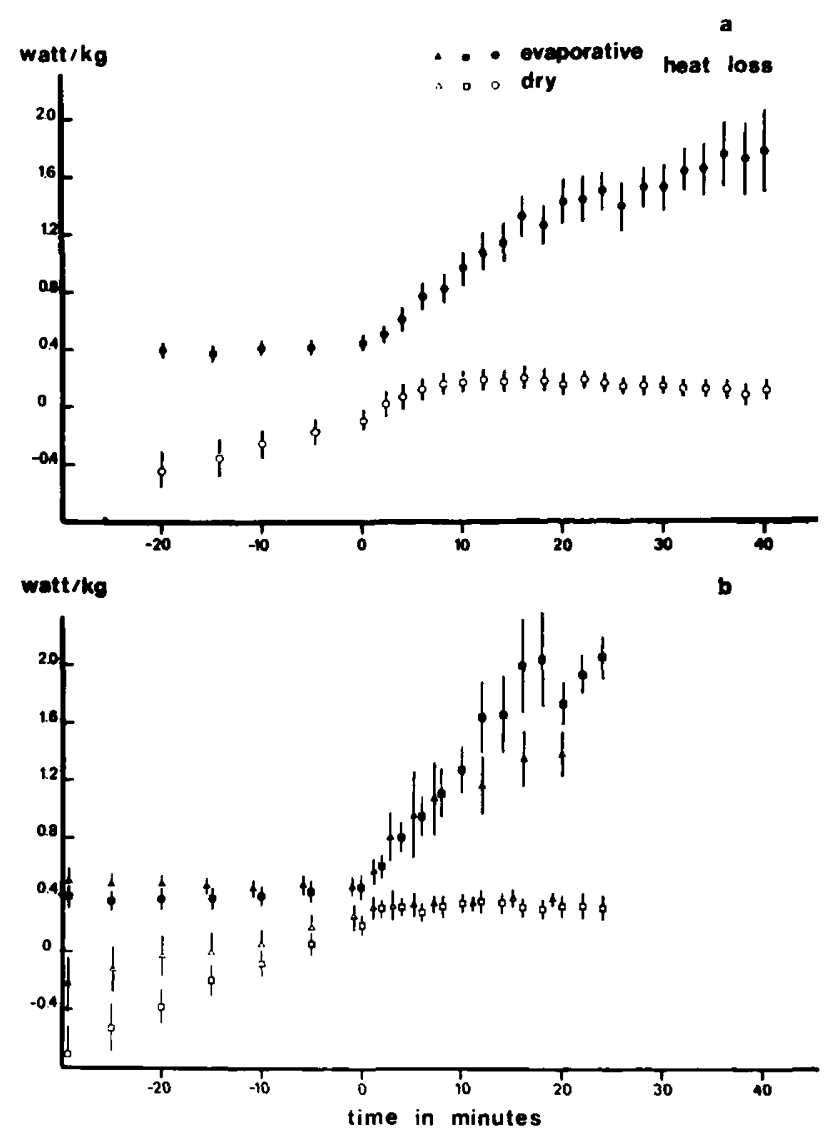

Fig. 3. Changes with time in evaporative $(\bullet, \mathbf{\square}, \mathbf{\Delta})$ and in dry heat losses $(O, \square, \triangle)$ for 22 full term $(\bullet, \bigcirc), 9$ small for date $(\square, \square)$, and 8 premature infants $(\Delta, \triangle)$. Each symbol represents the mean values af the given time; vertical bars represent SEM. Zero time was chosen arbitrarily as the beginning of sweating.

function of the esophageal temperature. In good agreement with Benzinger's set-point concept [5], at a definite deep body temperature, the thermoregulatory sweat reaction was elicited in each, the normal, the small for date, and the premature infants. Although we could find rather great variations in the threshold temperature for sweating in each group, the difference observed between normal and small for date and between normal and premature babies was highly significant $(P<0.005)$, with a mean value of $37.45^{\circ}$ (SE $\pm 0.06), 37.8^{\circ}(\mathrm{sE} \pm 0.07)$ and $37.76^{\circ}(\mathrm{sE} \pm 0.09)$, repectively.

In Figure 6 the evaporative heat loss is plotted against the forehead temperature. At first, a very pronounced decrease in the forehead temperature can be seen, which is followed by an only slightly increased evaporative heat loss, which indicates that probably must of the evaporation was originated from the fore- head. Later, the same drop in forehead temperature was accompanied by a far higher evaporative heat loss. The difference is due to the more intensive sweating of the forehead on the one hand and to the sweating of the other parts of the body on the other.

The onset of the sweat reaction could be ascertained by the increase of evaporative heat loss of the quiet, sleeping infants, and also by the drop in forehead temperature in both the quiet and crying infants. The fall in forehead temperature always appeared to be the first and the most pronounced drop when compared with other regions of the body.

The characteristics of the sweat reaction of the neonates are summarized in Table I.

The dry heat loss (radiation and convection) is at first negative in each group. When the mean skin temperature reaches the level of $37^{\circ}$ it becomes 0 and, with further increase in mean skin temperature, it re-

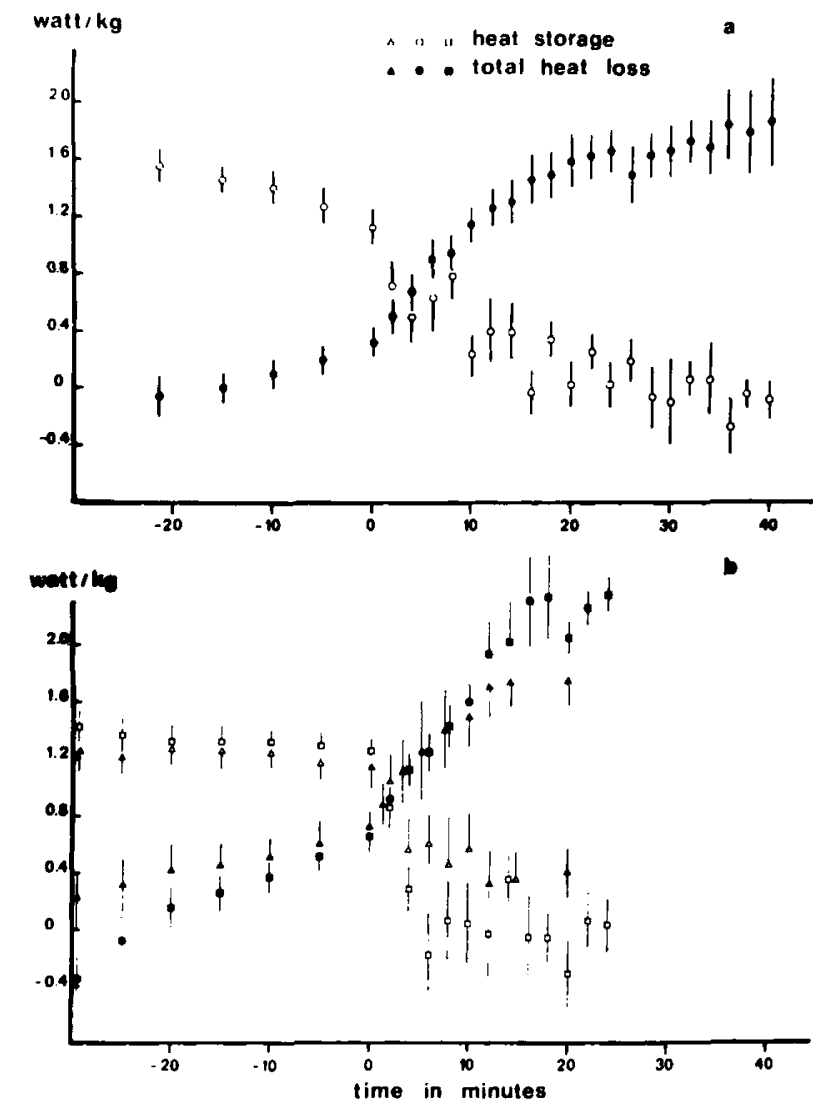

Fig. 4. Changes with time in heat storage $(\triangle, \bigcirc, \square)$ and in total heat loss $(\boldsymbol{\Lambda}, \bullet, \boldsymbol{\square})$ for 22 full term $(\bullet, \bigcirc), 9$ small for date $(\square, \square)$, and 8 premature infants $(\Delta, \triangle)$. Each symbol represents the mean values at the given time; vertical bars represent SEM. Zero time indicates the beginning of sweating. 
mains always positive. When the sweating is so effective that it can produce a cooling of the body surface, one can see a limited, statistically unsignificant fall in the dry heat loss (Fig. 3). After the onset of sweating the dry heat loss is significantly higher in the small for date and premature groups than in the normal group $(P<0.05)$.

As a result of the changes in the evaporative and dry heat losses, the total heat loss is at first negative, which indicates that this environment is heat gaining for the baby. Later, particularly after the sweating, it is rapidly increasing (Fig. 4).

\section{Heat Storage}

As is shown in Figure 4, there is an inverse relation between the heat storage and total heat loss. Until the beginning of sweating, heat storage is always positive. At this point of time, an abrupt fall can be seen and later all values are scattered around 0 . The latter indicates that a new thermal equilibrium is obtained. However, the premature infants were not able to reach this equilibrium, inasmuch as their heat storage remained always positive.

\section{Skin and Esophageal Temperatures}

The changes with time of mean skin and esophageal temperatures are shown in Figure 7 . It can be seen that both the internal and mean skin temperatures increase at nearly the same rate until the onset of sweating. The three groups do not differ from each other. In $15 \mathrm{~min}$ the normal infant attains the constant body temperature of $37.66^{\circ}$. The small for date infant begins to sweat at a body temperature of $37.8^{\circ}$ and he is able to maintain a new thermal equilibrium at an esophageal temperature of about $38^{\circ}$. The internal temperature of the premature infant is constantly increasing and the steady state is not reached by the end of experiment. It is interesting to note that the difference between the set-point of sweating and the new steady level of internal temperature was the same, i.e., $0.2^{\circ}$, in both the normal and small for date groups.

It is also shown in Figure 7 that the small for date and the premature infants first begin to sweat at a mean skin temperature of $37^{\circ}$, whereas the normal neonate begins to sweat at a significantly lower level, i.e., at $36.7^{\circ}(P<0.05)$. After sweating, the mean skin temperature either remains unchanged or diminishes in each group.

The changes with time of skin temperatures re-

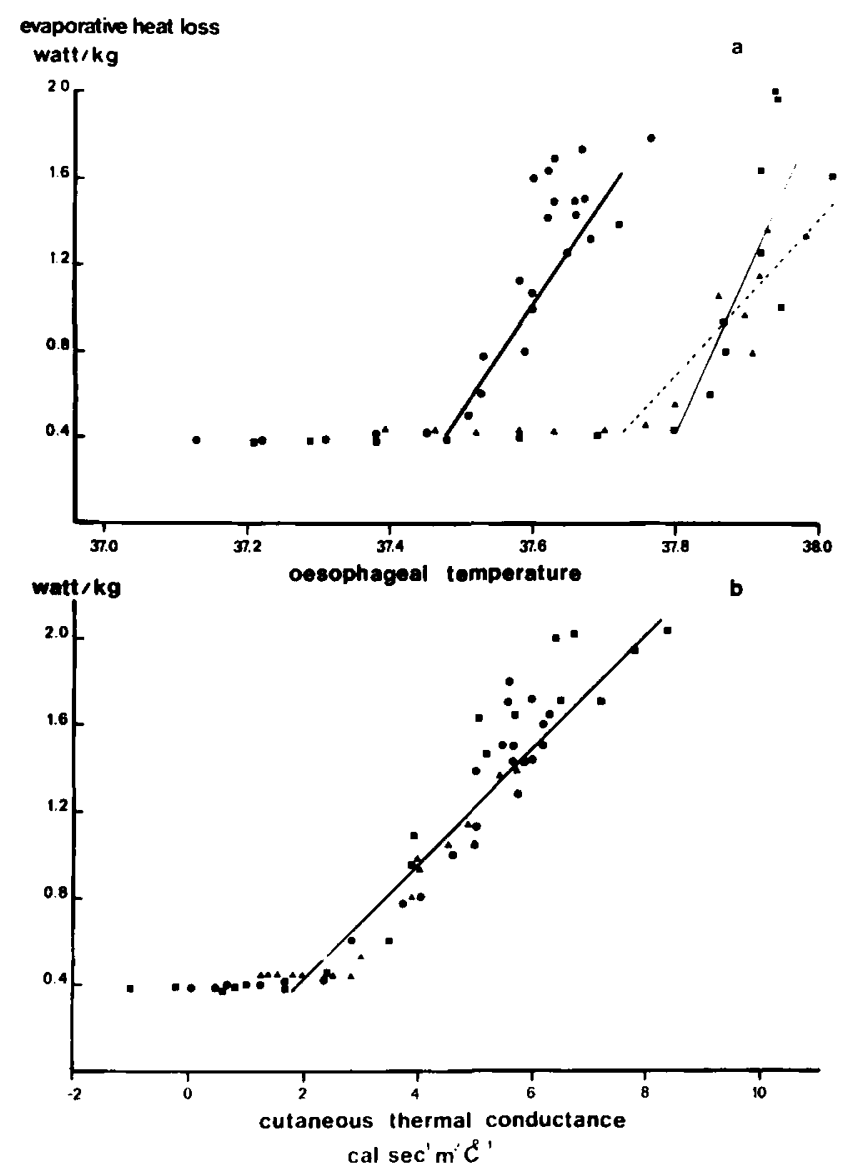

Fig. 5. a: relation between the esophageal temperature and evaporative heat loss for 22 full term $(\bullet,-$ : $y=4.704 \mathrm{x}-$ 175.714, $\mathrm{r}=0.825, P<0.005), 9$ small for date $(\square,-$ : $\mathrm{y}=$ $7.055 \mathrm{x}-266.205, \mathrm{r}=0.775, P<0.025)$, and 8 premature infants $(\Delta,---: \mathrm{y}=3.607 \mathrm{x}-135.66, \mathrm{r}=0.94, P<0.005) . b$ : evaporative heat loss as a function of cutaneous thermal conductance. For explanation of symbols see $a$. Regression equation: $\mathrm{y}=0.293 \mathrm{x}-$ $0.214, \mathrm{r}=0.926, P<0.001$.

corded at different sites of the body are shown in Figure 8. According to Burton's equation [8], the skin temperature before sweating is almost linearly proportional to the cutaneous blood flow under our experimental conditions. In this sense, one can say that the vasomotor response is most pronounced in the hand and foot and most limited in the abdominal and frontal skin.

From the beginning of sweating the skin temperature is decreasing in each area because of the evaporation of water. This phenomenon allows the conclusion that the forehead is the first to sweat, and is followed chronologically by the upperarm, hand, thigh, foot, and, finally, by the abdomen. Using the set-point hy- 


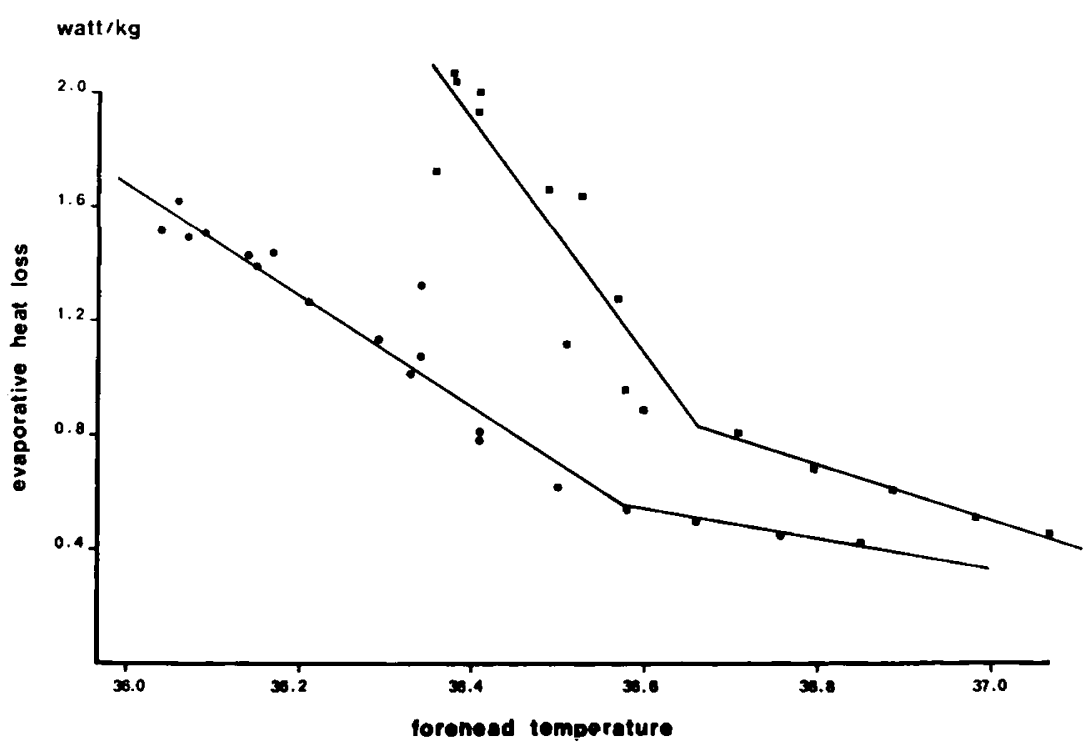

Fig. 6. Relation between the forehead temperature and evaporative heat loss of full term $(\bullet: \mathrm{y}=-0.535 \mathrm{x}+20.134$ and $\mathrm{y}=-1.95 \mathrm{x}+$ $71.881, \mathrm{r}=-0.981$ and $-0.946, P<0.025$ and 0.001$)$ and small for date infants $(\square, \mathrm{y}=-0.944 \mathrm{x}+35.449$ and $\mathrm{y}=-4.072 \mathrm{x}+$ $150.121, \mathrm{r}=0.996$ and $-0.853, P<0.001$ and 0.005$)$.

Table I. Characteristics of sweat reaction of full term, full sized, small for date, and premature infants subjected to ambient temperature of $37^{\circ}$ and relative humidity of $50 \%$ on 1st day of life

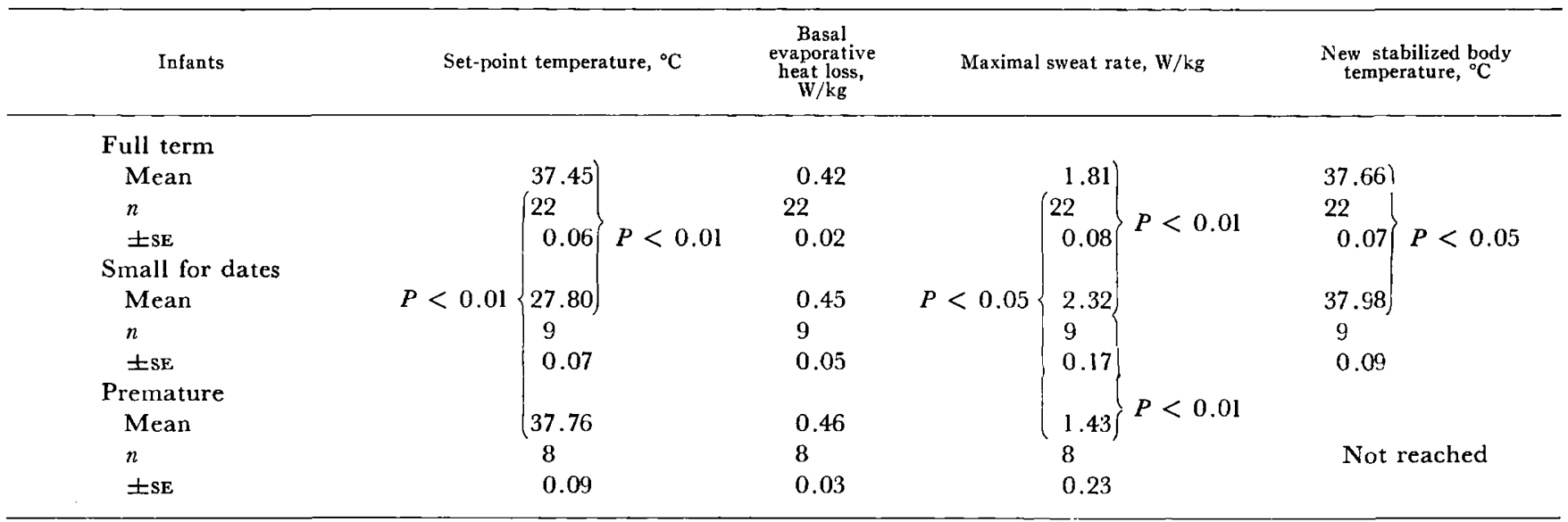

pothesis, it may be said that the threshold body temperature for sweating is lowest for the forehead, and with increasing body temperature the other regions which have a higher set-point will be activated to sweat.

\section{Cutaneous Thermal Conductance}

The variations in cutaneous thermal conductance as a function of time of exposure to the ambient temperature of $37^{\circ}$, and also as a function of internal temperature are shown in Figure 9. It can be seen that during about the first $20 \mathrm{~min}$ conductance is negative, a fact which indicates that heat is transferred from the surface to the core. After the beginning of sweating, a rapid rise was observed which reached maximal value at an esophageal temperature of $37.6^{\circ}$ in normal and $37.93^{\circ}$ in small for date and premature groups.

In Figure $5 b$, the cutaneous thermal conductance is plotted against the evaporative heat loss. From these data it is evident that the sweat reaction is preceded by the increase in skin blood flow, and, when sweating is induced, the relation becomes linear in each group. 


\section{Metabolic Rate}

In Figure 10 the changes in the metabolic rate are shown. It can be seen that the neonate subjected to the same heat stress for a longer period of time responds with a continuously increasing metabolic rate. Although this increase is statistically significant in each group $(P<0.01$ and $P<0.005)$, the rates for small for date and premature infants tend to increase more rapidly, and to reach a significantly higher level than that observed in their normal controls $(P<0.05)$.

It is interesting to note that at the beginning of sweating a sharp fall in the metabolic rate was found in each group, which was followed by the same rise after a short period of time. These changes seem to be due to the rapid changes in heat storage. It is also shown in Figure 10 that there is a strong positive correlation between deep body temperature and metabolic rate; increasing esophageal temperature is accompanied by a steady rise in metabolic rate.

Comparison of these data with those obtained in our previous study [36], makes evident that the metabolic rate at ambient temperature of $37^{\circ}$ is far lower than that found at "neutral" temperature (at $32^{\circ}$ metabolic rate $=2.25 \mathrm{~W} / \mathrm{kg}$; $\mathrm{sE} \pm 0.06$ ).

Because these findings were observed in two different, but comparable groups of newborn infants, we subjected two infants to both neutral and warm environments in order to compare the metabolic responses more exactly. As is shown in Table II, the stabilized metabolic rate at an ambient temperature of $37^{\circ}$ was lower than under neutral conditions by $16.3 \%$ and $19.2 \%$.

\section{Activity}

All infants included in the study remained quiet and were sleeping during the whole experiment.

The respiratory rate of normal, small for date, and premature infants rose significantly from $43 / \mathrm{min}$ (SE \pm 2.2 ), to $63 / \mathrm{min}$ (SE $\pm 4.14, P<0.01$ ); from $44 / \mathrm{min}$ (sE \pm 4.9 ) to $79 / \mathrm{min}(\mathrm{sE} \pm 5.3, \mathrm{P}<0.001$ ); and from $52 / \mathrm{min}(\mathrm{sE} \pm 4.2)$ to $74 / \mathrm{min}(\mathrm{sE} \pm 4.9, P<0.01$ ), respectively.

It was striking that this elevation was not achieved by a continuous increase. Usually, the respiratory rate sharply augmented some minutes before the beginning of sweating.

Eight infants (group IV) with crying and vigorous activity for about 10-15 min were studied separately. In this group the evaporative heat loss increased before the sweating as a consequence of the increased

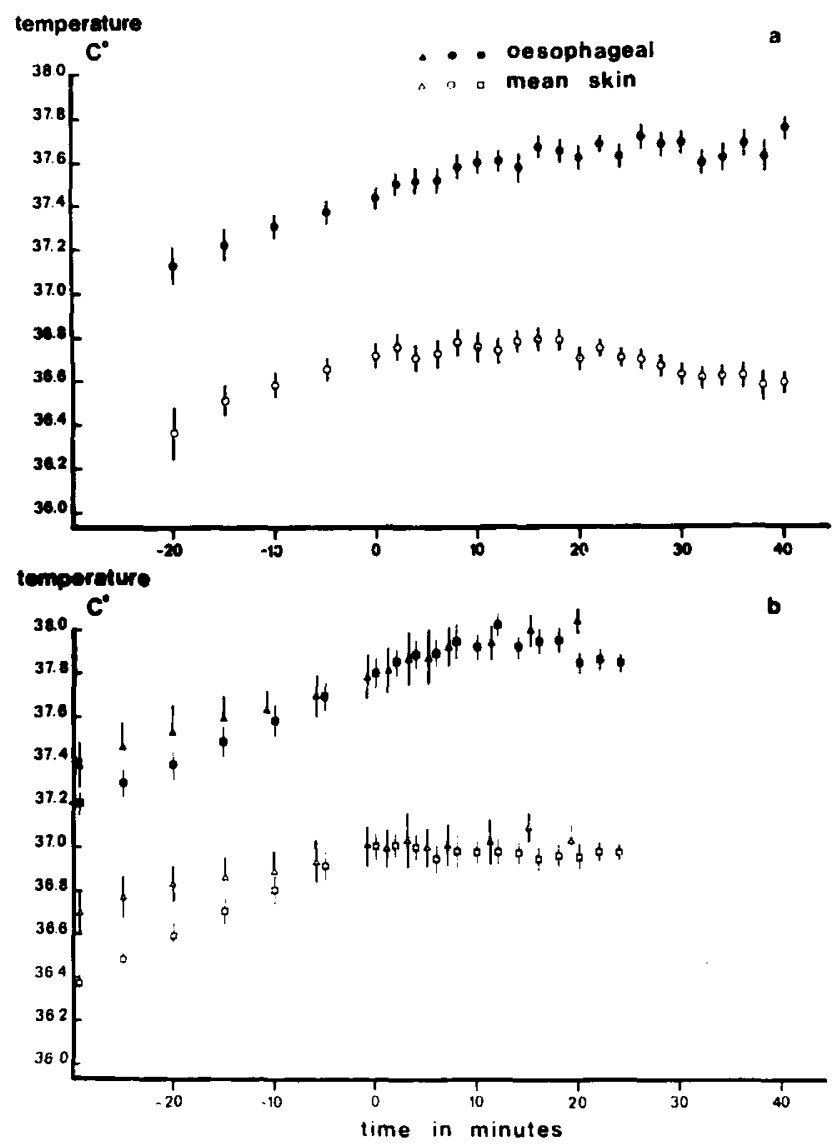

Fig. 7. Changes with time in esophageal $(\boldsymbol{\Lambda}, \boldsymbol{0}, \boldsymbol{\square})$ and in mean skin temperatures $(\triangle, \bigcirc, \square)$ for 22 full term $(\bullet, O), 9$ small for date $(\square, \square)$, and 8 premature infants $(\Delta, \triangle)$. Each symbol represents the mean values at the given time; vertical bars represent sEM. Zero time indicates the beginning of sweating.

respiratory heat loss. Therefore, the set-point was indicated only by the dropping forehead temperature. When this was observed, the experiment was discontinued to verify visually the sweat reaction.

The mean threshold temperature for sweating during activity was $37.09^{\circ}$ ( $\mathrm{SE} \pm 0.04$ ) and proved to be significantly lower than the set-point of $37.45^{\circ}$ found in quiet, sleeping neonates $(P<0.005)$.

\section{Changes in Sweat Response on 3rd Day of Life}

In 20 cases the examination was repeated on the $3 \mathrm{rd}$ day of life under the same experimental conditions as it was performed on the 1st day. As indicated in Table III, this group was divided into two subgroups according to the behavior of set-point temperature: (subgroup a) the set-point temperature decreased; (subgroup b) the set-point temperature increased or remained unchanged. 


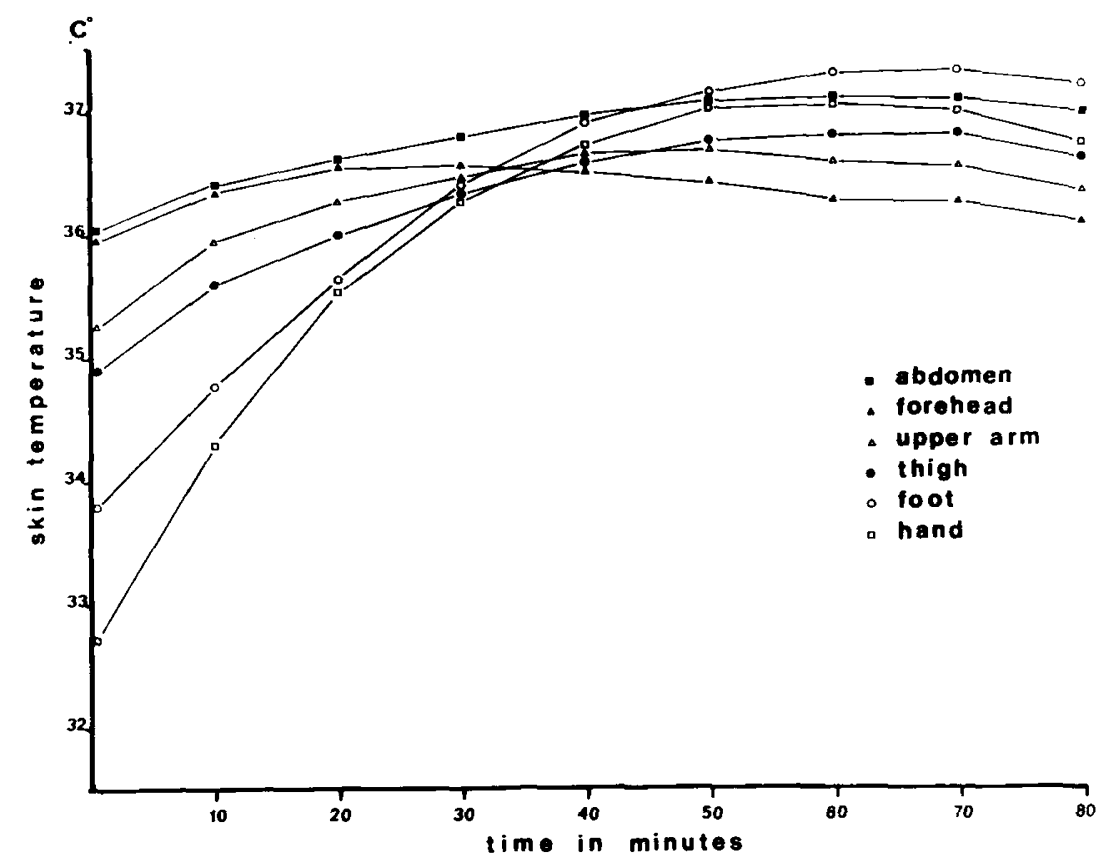

Fig. 8. Changes with time in the skin temperatures recorded from six different sites for 22 full term infants.

It can be seen that in subgroup a the threshold temperature for sweating is significantly lower on the 3rd day $(P<0.01)$, but both basal and maximal values of evaporative heat loss remained practically unchanged.

In subgroup $b$, the basal and maximal levels of evaporative heat loss were also nearly the same, but the increase of set-point proved to be statistically significant $(P<0.05)$.

It is also shown by Table III that, when the setpoint was higher on the 3rd day, the new thermal equilibrium was reached at a higher body temperature, whereas a decreasing set-point resulted in the stabilization of the deep body temperature at a lower level.

Comparison of the two subgroups yielded observations of a statistically significant difference in weight loss from the lst to the 3rd day $(P<0.05)$. Therefore, one can assume that the increase of set-point of sweating may be caused by the greater weight loss, i.e., by dehydration.

\section{Discussion}

\section{Sweating}

Evaporation of the water from the skin has long been recognized as a main source of elimination of heat from the body in a warm environment. During the last few years the ability of the newborn infant to sweat and the factors which influence the sweat reaction to different stimuli have been studied repeatedly.

Brück [6] found that the full term newborn infant was able to sweat as early as on the 1st day of life if the ambient and rectal temperatures were as high at $35^{\circ}$ to $37^{\circ}$, and $37.5^{\circ}$ to $37.9^{\circ}$, respectively.

This finding was confirmed by Foster et al. [13, 14] and by Hey and Katz [24]. The observed that thermoregulatory sweating occurred in infants born within 3 weeks of term when the ambient temperature exceeded $34-35^{\circ}$ and the rectal temperature exceeded $37.2^{\circ}$ during the first 10 days of life. It was also found that the threshold body temperature for sweating decreased and the maximal sweat reaction increased with increasing postnatal age. Their data provided evidence that functional development of sweat mechanism was determined by gestational age.

We could also demonstrate that not only threshold body temperature for sweating, but also maximal sweat reaction greatly depended on gestational age.

The importance of gestational age in the maturation of glandular reactivity was demonstrated also by intradermal pharmacologic stimulation with epinephrine, acetylcholine [3, 14, 19], nicotine, and pilocarpine [18].

Inasmuch as, in the present study, we observed a wide variation in the sweat reaction of newborn in- 


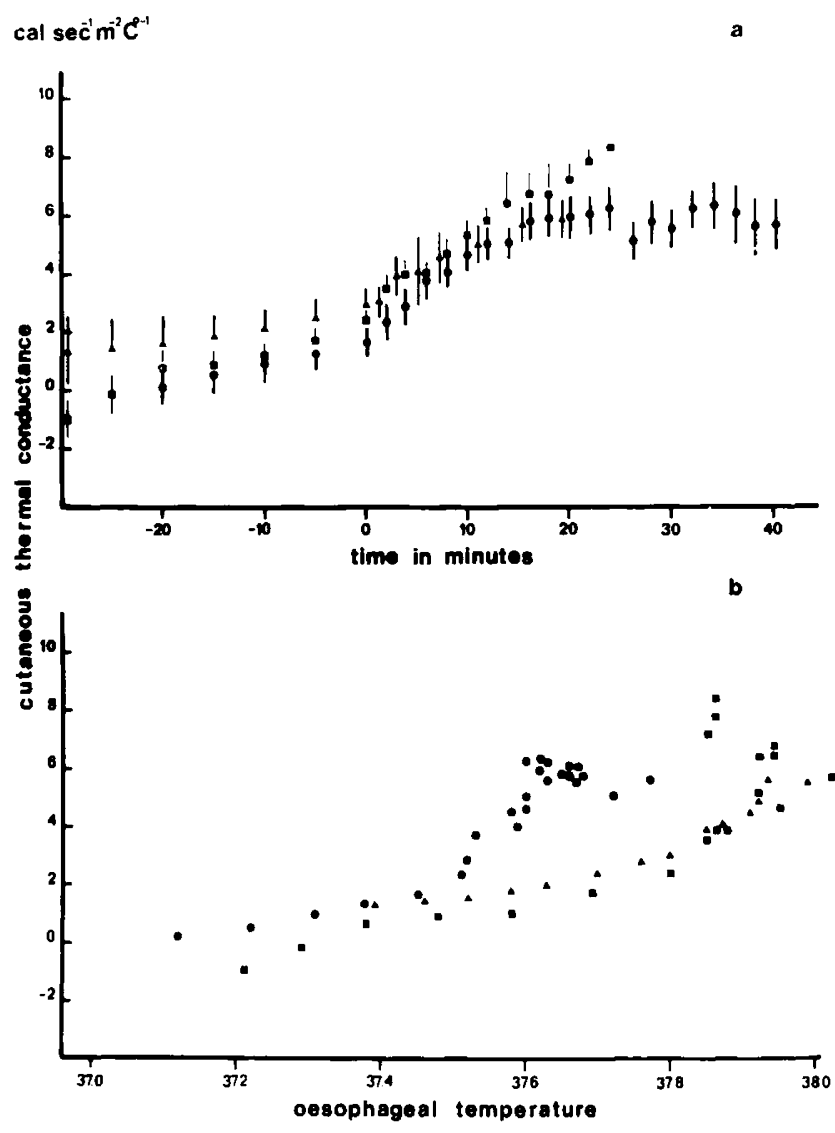

Fig. 9. a: changes with time in the cutaneous thermal conductance for 22 full term (.), 9 small for date $(\square)$, and 8 premature infants $(\boldsymbol{\Delta})$. Each symbol represents the mean value at the given time; vertical bars represent sEM. $b$ : relation between the cutaneous thermal conductance and the esophageal temperature. For explanation of symbols see $a$.

fants of the same gestational age under the same experimental conditions, it must be assumed that the sweat response to thermal stimuli is influenced by several factors, and not only by gestational age.

The most striking result was the increase in threshold body temperature for sweating in small for date infants. This shift may be due to: (1) physical characteristics of the skin [11]; (2) dehydration, although it has been recently suggested that the extracellular space of the small for date infants is expanded if it is expressed as percentage of the body weight $[9,10]$; (3) chronic hypoxia as a consequence of the chronic fetal distress [20].

It is known that infants with severe malformation of the central nervous system fail to sweat as a reaction either to warmth or to direct chemical stimulation [14, 15]. It can be assumed that slight hypoxic brain dam-

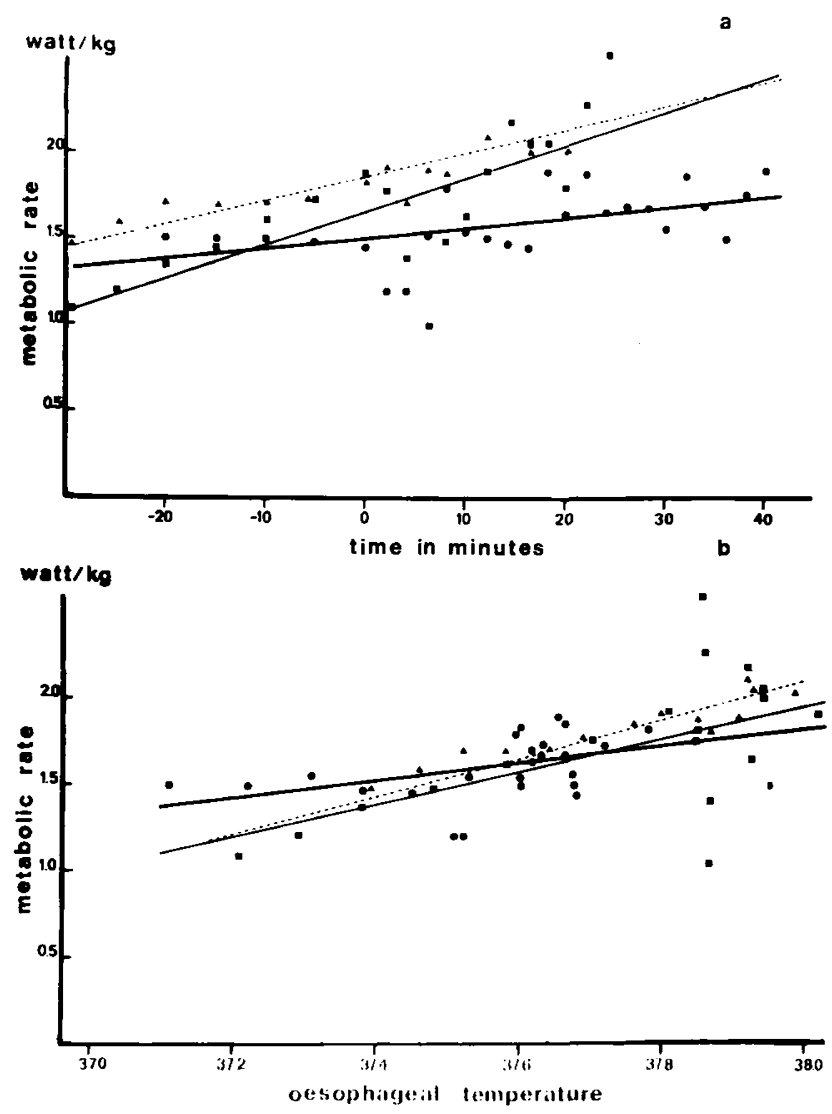

Fig. 10. a: changes with time in the metabolic rate for 22 full term $(\bullet,-\mathrm{y}=0.006 \mathrm{x}+1.503, \mathrm{r}=0.559, P>0.01), 9$ small for date $(\square,-\mathrm{y}=0.019 \mathrm{x}+1.668, \mathrm{r}=0.757, P<0.005)$, and 8 premature infants $(\Lambda,---: \mathrm{y}=0.011 \mathrm{x}+1.838, \mathrm{r}=0.900$ $P<0.001) . b$ : metabolic rate as a function of esophageal temperature for 22 full term $(\mathrm{y}=0.525 \mathrm{x}-18.113, \mathrm{r}=0.432, P<0.025)$, 9 small for date $(\mathrm{y}=1.001 \mathrm{x}-36.064, \mathrm{r}=0.571, P<0.005)$, and 8 premature infants $(\mathrm{y}=0.826 \mathrm{x}-29.375, \mathrm{r}=0.865, P<$ $0.005)$. The symbols are the same as in $a$ and represent mean values at the given time.

Table II. Metabolic rate at ambient temperature of $32^{\circ}$ in two individual cases

\begin{tabular}{cccccc}
$\begin{array}{c}\text { Birth } \\
\text { weight, } \\
\text { g }\end{array}$ & $\begin{array}{c}\text { Gestational } \\
\text { age, } \\
\text { wk }\end{array}$ & $\begin{array}{c}\text { Age, } \\
\text { hr }\end{array}$ & $\begin{array}{c}\text { Metabolic } \\
\text { rate at 32 } \\
\mathbf{W} / \mathrm{kg}\end{array}$ & $\begin{array}{c}\text { Metabolic } \\
\text { rate at 37 } \\
\mathbf{W} / \mathrm{kg}\end{array}$ & $\begin{array}{c}\text { Decrease in } \\
\text { metabolic rate, } \\
\%\end{array}$ \\
\cline { 1 - 2 } 3,272 & 42 & 18 & 1.96 & 1.64 & 16.27 \\
3,220 & 40 & 8 & 2.25 & 1.82 & 19.20 \\
\hline
\end{tabular}

age may be manifested only in the elevation of the set-point of sweating.

The effect of muscular exercise on the thermoregulatory responses has been investigated widely in the adult physiology. There is increasing evidence that during work the sweat rate is higher than at rest for 
Table III. Relation between physiologic weight loss and ability to sweat of newborn infant at ambient temperature of $37^{\circ}$

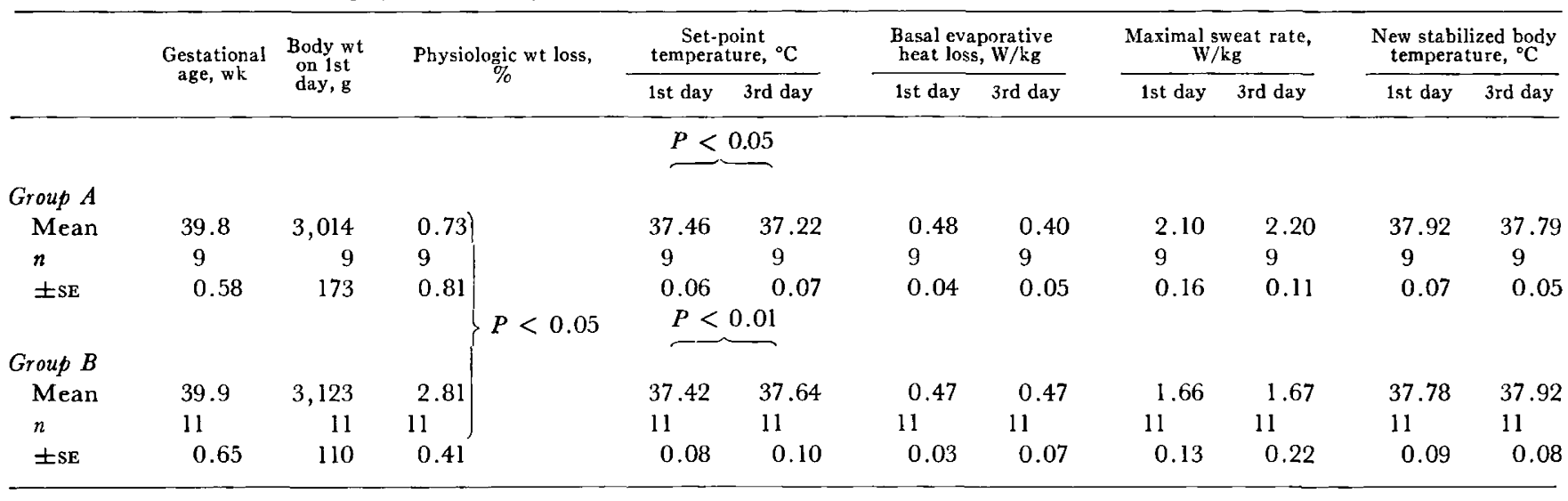

the same internal temperature, and also that the muscular activity seems to decrease the set-point temperature for all thermoregulatory responses [21, 26].

For the newborn infant, it was not possible to establish the exact relation between the muscular activity and the sweat reaction, because we had no method to measure quantitatively the muscular exercise. In addition, all experiments were discontinued at the beginning of sweating in order to be sure that the sweat response had been elicited.

Nevertheless, it can be stated that vigorous activity of the neonate accompanied by crying and restlessness for about $10-15$ min resulted in a significant decrease of the threshold temperature for sweating. It was observed also by Foster et al. [14] that the sweat response of the neonate was often initiated or augmented in intensity when the infant became restless or cried.

We found that infants on the 3rd day of life who did not lose weight had a shift downward in the setpoint temperature. The phenomenon may be explained by the postnatal development of the control system as it was found by Foster et al. [14] and Hey et al. [24], although the inductive effect of the first experiment (on the 1st day) also must be taken into consideration, because in experiments on adults the sweat gland training by drugs or thermal stress resulted in decreased threshold temperature and in increased sweat rate $[12,16]$. A similar phenomenon which occurs during the neonatal period has been observed previously [14].

When infants had lost about $3 \%$ of body weight, the set-point temperature went up, but the maximal rate of sweating remained unchanged. It is interesting to note that in experiments on adults dehydration of about the same degree reduced the sweat rate [27], and the oral temperature was slightly higher by $0.1^{\circ}[31]$.
In our study the term "set-point" was used for the body temperature at which the sweat reaction of the forehead was elicited. Because the other parts of the body begin to sweat later on and at higher body temperature, it would be more reasonable to speak about separate set-points for each main sweating area.

The comparison between the thermoregulatory sweat reaction of the neonate and the adult exposed to a hot environment allows the following conclusions to be drawn: (1) the set-point temperature at which sweating is elicited is lower in adults [5] than in neonates; (2) in adults sweating occurs almost simultaneously on the different skin areas at nearly the same deep body temperature, whereas, in the neonate, each area is activated at different threshold temperature; (3) the increase in sweating is proportional to the rise of internal temperature in both adults [5] and neonates; (4) the rate of sweating of the adult is far higher at a given deep body temperature [5] than that of the newborn infant.

\section{Metabolic Rate}

It is generally accepted that the full term newborn infant responds to cold with an increasing metabolic rate, whereas the data which concern metabolic response to a hot environment are scanty and contradictory. The experimental basis of the view that the heat production of the neonate in an environment warmer than the neutral temperature range is increased must be questioned.

With increasing ambient temperature, up to $38-40^{\circ}$, the metabolic rate either remains unchanged or increases insignificantly [1, 2, 23, 25, 29, 33].

Recently, Grausz [17] indicated that there was a statistically significant decrease $(30 \%)$ in oxygen con- 
sumption at an ambient temperature of $40^{\circ}$ as compared with $35^{\circ}$.

Furthermore, Ryser and Jéquier [30] found that the metabolic rate continuously diminished as the environment became by $2^{\circ}$ or $4^{\circ}$ warmer than the neutral temperature.

In the present study, it has been demonstrated that the metabolic rate at an ambient temperature of $37^{\circ}$ displays a drop of about $34 \%$ when compared with the results obtained under neutral ambient conditions [36].

Although the metabolic rate of the normal full term infants gradually increased during our experiment, after reaching the new steady state, it remained by about $20 \%$ lower than under neutral conditions.

The higher values found in small for date infants are in good agreement with the concept of the relative hypermetabolism of growth-retarded newborn infants [34, 35].

The increase in respiratory rate does not correlate well with the metabolic rate, and one can assume that the appearance of a more rapid rate of respiration is a thermoregulatory response to rising body temperature.

Our data suggest that the term "neutral thermal environment" of the neonate must be reconsidered. By definition, the neutral thermal environment is a condition at which heat production is minimal, body temperature remains unchanged, and the behavior of the baby is quiet for a long period of time.

The heat-gaining environment, after reaching the new thermal equilibrium, corresponds to all of these criteria, although the sweating, the increased cutaneous blood flow, and the increased respiratory rate are obvious signs of thermal discomfort.

\section{Summary}

The thermal balance was studied in 8 premature, 22 full term, and 9 small for date infants on the 1st day of life under the same environmental conditions (temperature $37^{\circ}$, relative humidity $50 \%$, air flow 30 liter/ min) using gradient layer direct calorimetry.

Twenty neonates were studied again on the 3rd day of life.

Evaporative, dry, and total heat losses, as well as the esophageal and mean skin temperatures, were measured. Heat storage, cutaneous thermal conductance, and metabolic rate were calculated.

The following conclusions were made.

1. All infants were able to raise their evaporative heat loss by active sweating. Maximal sweat rate was related to gestational age.
2. The set-point temperature for sweating showed large variations. It seems to be influenced by many factors such as gestational age, postnatal age, muscular activity, physical characteristics of the skin, dehydration, and the function of the central nervous system.

3. Evolution of dry heat loss (convection, radiation) was related to the mean skin temperature. At first it was negative, and, when the mean skin temperature exceeded $37^{\circ}$, it became positive.

4. The heat storage decreased sharply and remained constant around 0 after the onset of the sweat reaction. It was inversely related to the total heat loss.

5. Full term and small for date infants were able to reach and maintain a new thermal equilibrium and stabilize body temperature at levels as high as about $37.7^{\circ}$ and $38^{\circ}$, respectively.

6. Cutaneous thermal conductance preceded the increase of evaporative heat loss and its reaching of maximal value. The most pronounced vasomotor response was seen on the hands and legs.

7. At the beginning of the experiment, the metabolic rate of normal full term infants was about $34 \%$ lower than under neutral thermal conditions; however, after reaching the new steady state, this difference decreased to about $20 \%$.

The metabolic rate of small for date and premature infants was significantly higher than that of normal infants.

\section{References and Notes}

1. Adams, F. H., Fujiwara, F., Spars, R., and Hodgman, J.: Temperature regulation in premature infants. Pediatrics, 33: 487 (1964).

2. Adamsons, K., Gandy, G. M., and James, L. S.: The influences of thermal factors upon oxygen consumption of the newborn human infant. J. Pediat., 66: 495 (1965).

3. Behrendt, H., AND Green, M.: Drug induced localized sweating in full-size and low-birth-weight neonates. Amer. J. Dis. Child., 117: 299 (1969).

4. Benzinger, T. H., AND KITZinger, C.: Gradient layer calorimetry and human calorimetry. Temp. Meas. Contr. Sci. Ind., 3: 87 (1963).

5. Benzinger, 'T. H., Kitzinger, C., and Pratt, A. W.: The human thermostat. Temp. Meas. Contr. Sci. Ind., 3: 637 (1963).

6. BRücK, K.: Temperature regulation in the newborn infant. Biol. Neonatorum, 3: 65 (1961).

7. Brück, K., PARmeleE, A. H., ANd Brück, M.: Neutral temperature range and range of "thermal comfort" in premature in. fants. Biol. Neonatorum, 4: 32 (1962).

8. Burton, A. C., And Murlin, A. C.: Human calorimetry. III. Temperature distribution, blood flow and heat storage in the body in basal condition and after ingestion of food. $\mathrm{J}$. Nutr., 9: 281 (1935).

9. Cassady, G.: Bromide space studies in infants of low birth weight. Pediat. Res., 4: 14 (1970). 
10. Cassady, G, and Milstead, R. R.: Antipyrine space studies and cell water estimates in infants of low birth weight. Pediat. Res., 5: 673 (1971).

11. Clifford, S. H.: Postmaturity with placental dysfunction. J. Pediat., 4t: 1 (1954).

12. Collins, K. J., Crocford, G. W., and Weiner, J. S.: Sweat gland training by drugs and thermal stress. Arch. Environ. Health, 11: 407 (1965).

13. Foster, K. G., Hey, E. N., And Katz, G.: Eccrine sweat gland function in the newborn baby. J. Physiol., 198: 364 (1968).

14. Foster, K. G., Hey, E. N., ANd Katz, G.: The response of sweat glands of the newborn baby to thermal stimuli and to intradermal acetylcholine. J. Physiol., 203: 13 (1969).

15. Foster, K. G., Hey, E. N., And O'Connell, B.: Sweat function in babies with defects of the central nervous system. Arch. Dis. Childhood, 46: 444 (1971).

16. Fox, R. H., Goldsmith, R., Hampton, J. F. G., and Lewis, H. E.: The nature of the increase in sweating capacity produced by heat acclimatisation. J. Physiol., 171: 368 (1964).

17. Grausz, J. P.: The effect of environmental temperature changes on the metabolic rate of newborn babies. Acta Pediat. Scand., 57: 98 (1968).

18. Green, M., AND BeHrendt, H.: Sweating capacity of neonates. Nicotine induced axon reflex sweating and the histamine flare. Amer. J. Dis. Child., 118: 725 (1969).

19. Green, M., ANd Behrendt, H.: Drug induced localized sweating in neonates: Responses to exogenous and endogenous acetylcholine. Amer. J. Dis. Child., 120: 434 (1970).

20. Grüenwald, P.: Chronic fetal distress and placental insufficiency. Biol. Neonatorum, 5: 215 (1963).

21. Hammel, H. T.: Regulation of internal body temperature. Annu. Rev. Physiol., 30: 641 (1968).

22. Hardy, J. D., and Soderstrom, G. F.: Heat loss from the nude body and peripheral blood flow at temperatures of $22^{\circ} \mathrm{C}$ to $35^{\circ}$ C. J. Nutr., 16: 493 (1938).

23. HeY, E. N.: The relation between environmental temperature and oxygen consumption in the newborn baby. J. Physiol., 200: 589 (I969).

24. HEY, E. N., AND KATZ, G.: Evaporative water loss in the newborn baby. J. Physiol., 200: 605 (1969).

25. Hill, L. C., and Rahimtulla, K. A.: Heat balance and the metabolic rate of newborn babies in relation to environmental temperature; and the effect of age and weight on basal metabolic rate. J. Physiol., 180: 239 (1965).
26. JÉquier, E., Dolivo, M., And Vannotti, A.: Temperature regulation in exercise: The characteristics of proportional control. J. Physiol. (Paris), 63: 303 (1971).

27. Leithead, C. S., and Pallister, M. A.: Observations on dehydration and sweating. Lancet, ii: 114 (1960).

28. Lubchenco, L. O., Hansman, C., Dressler, M., and Boyd, E.: Intrauterine growth as estimated from liveborn birthweight data at 24 to 42 weeks of gestation. Pediatrics, 32: 793 (1963).

29. Miller, H. C., Behrle, F. C., Nieman, J. L., Driver, R., and Dudping, B. A.: Oxygen consumption in newborn premature infants. Amer. J. Dis. Child., 103: 39 (1962).

30. Ryser, G., AND JÉquier, E.: Study by direct calorimetry of of thermal balance on the first day of life. Eur. J. Clin. Invest., 2: 176 (1972).

31. Senay, L. C., And Christensen, M. L.: Cutaneous circulation during dehydration and heat stress. J. Appl. Physiol. 20: 278 (1965).

32. Silverman, W. A., and Agate, F. J.: Variations in cold resistance among small newborn infants. Biol. Neonatorum, 6 : 113 (1964).

33. Silverman, W. A., Sinclair, J. C., and Agate, F. J.: The oxygen cost of minor changes in heat balance of small newborn infants. Acta Paediat. Scand., 55: 294 (1966).

34. Sinclair, J. C.: Heat production and thermoregulation in the small for dates infant. Ped. Clin. N. Amer., 17(1): 147 (1970).

35. Sinclair, J. C., AND Silverman, W. A.: Relative hypermetabolism in undergrown human neonates. Lancet, $i i: 49$ (1964).

36. Sulyok, E., JÉQuIER, E., AND RySER, G.: Effect of relative humidity on thermal balance of the newborn infant. Biol. Neonatorum, accepted for publication.

37. Thermistor probe 402, Yellow Springs Instrument Company, Yellow Springs, Ohio.

38. Thermistor probe 426, Yellow Springs Instrument Company, Yellow Springs, Ohio.

39. We thank Professor W. Merz of the Department of Obstetrics and Gynecology and Professor A. Vannotti of the Department of Medicine for their support in this study. Similarly, we are grateful to Dr. G. Ryser for his valuable advice and to Mrs. M. C. van Gelder for her technical assistance.

40. This research was supported by the Nestlé Company.

41. Requests for reprints should be addressed to: E. Sulyox, M.D., Department of Pediatrics, University of Pécs, Pécs, Hungary. 42. Accepted for publication June 19, 1973 